\title{
Multiple solutions to impulsive differential equations
}

Hongmei Bao*

\section{"Correspondence: hmbao001@sina.com \\ Faculty of Mathematics and Physics, Huaiyin Institute of Technology, Huaian, Jiangsu 223003, P.R. China}

\begin{abstract}
In this paper, we study the existence of a second-order impulsive differential equations depending on a parameter $\lambda$. By employing a critical point theorem, the existence of at least three solutions is obtained.
\end{abstract}

MSC: $34 \mathrm{~A} 37 ; 34 \mathrm{~K} 10$

Keywords: multiple solutions; critical point theorem; impulses

\section{Introduction}

In recent years, the study of the existence of solutions to impulsive differential equation has aroused extensive interest, we refer the reader to [1-5] and the references therein.

In [1], by using some existing critical point theorems, Xie and Luo investigated the existence of multiple solutions of the following Neumann boundary value problem:

$$
\begin{aligned}
& -\left(p(t) u^{\prime}(t)\right)^{\prime}+q(t) u(t)=\lambda f(t, u(t)), \quad t \neq t_{j}, t \in[0,1], \\
& \Delta p\left(t_{j}\right) u^{\prime}\left(t_{j}\right)=I_{j}\left(u\left(t_{j}\right)\right), \quad j=1,2, \ldots, m, \\
& u^{\prime}(0)=u^{\prime}(1)=0 .
\end{aligned}
$$

In [2], Liang and Zhang considered the following boundary value problems:

$$
\begin{aligned}
& -\left(p(t) u^{\prime}(t)\right)^{\prime}=f(t, u(t)), \quad t \neq t_{j}, t \in[0, T], \\
& \Delta p\left(t_{j}\right) u^{\prime}\left(t_{j}\right)=I_{j}\left(u\left(t_{j}\right)\right), \quad j=1,2, \ldots, m, \\
& u(0)=u(T), \quad p(0) u^{\prime}(0)=p(T) u^{\prime}(T) .
\end{aligned}
$$

The authors gave some criteria to guarantee that the problem has at least one solution under some different conditions.

In [3], Li and Shen were concerned with the existence of three solutions for the following boundary value problems:

$$
\begin{aligned}
& -u^{\prime \prime}(t)=\lambda f(u(t)), \quad t \neq t_{j}, t \in[0,1], \\
& \Delta u^{\prime}\left(t_{j}\right)=I_{j}\left(u\left(t_{j}\right)\right), \quad j=1,2, \ldots, m, \\
& u(0)=u(1)=0 .
\end{aligned}
$$

(c) The Author(s) 2017. This article is distributed under the terms of the Creative Commons Attribution 4.0 International License (http://creativecommons.org/licenses/by/4.0/), which permits unrestricted use, distribution, and reproduction in any medium, provided you give appropriate credit to the original author(s) and the source, provide a link to the Creative Commons license, and indicate if changes were made. 
Motivated by the previous mentioned paper, in this paper, we will study the existence of at least three solutions for the following boundary value problems:

$$
\begin{aligned}
& -\left(p(t) u^{\prime}(t)\right)^{\prime}+u(t)=\lambda f(t, u(t)), \quad t \neq t_{j}, t \in[0,1], \\
& \Delta p\left(t_{j}\right) u^{\prime}\left(t_{j}\right)=I_{j}\left(u\left(t_{j}\right)\right), \quad j=1,2, \ldots, m, \\
& u^{\prime}(0)=u^{\prime}(1)=0
\end{aligned}
$$

where $0=t_{0}<t_{1}<\cdots<t_{m}<t_{m+1}=1, p \in P C^{1}([0,1]), f \in C([0,1] \times R, R), I_{j} \in C(R, R)$, $j=1,2, \ldots, m, \Delta p\left(t_{j}\right) u^{\prime}\left(t_{j}\right)=p\left(t_{j}^{+}\right) u^{\prime}\left(t_{j}^{+}\right)-p\left(t_{j}^{-}\right) u^{\prime}\left(t_{j}^{-}\right), p\left(t_{j}^{+}\right) u^{\prime}\left(t_{j}^{+}\right)$and $p\left(t_{j}^{-}\right) u^{\prime}\left(t_{j}^{-}\right)$denote the right and the left limits, respectively, $\lambda \in[0,+\infty)$ is a real parameter.

\section{Preliminaries}

Let $p_{0}=\min _{t \in[0,1]} p(t)>0, M_{0}=\max \left\{\frac{1}{p_{0}}, 1\right\}, X=W^{1,2}[0,1]$ with the norm

$$
\|u\|=\left(\int_{0}^{1}\left(p(t)\left|u^{\prime}(t)\right|^{2}+|u(t)|^{2}\right) d t\right)^{\frac{1}{2}} .
$$

Define the norm in $C([0,1])$ by $\|u\|_{\infty}=\max _{t \in[0,1]}|u(t)|$.

Lemma 2.1 For any $u \in X$, we have $\|u\|_{\infty} \leq \sqrt{2 M_{0}}\|u\|$.

Proof For $u \in X$ by the mean-value theorem, there exists $\tau \in(0,1)$ such that $\int_{0}^{1} u(s) d s=$ $u(\tau)$. Hence, for $t \in[0,1]$, we have

$$
\begin{aligned}
|u(t)| & =\left|u(\tau)+\int_{\tau}^{t} u^{\prime}(s) d s\right| \leq|u(\tau)|+\int_{0}^{1}\left|u^{\prime}(s)\right| d s \\
& \leq \int_{0}^{1}|u(s)| d s+\int_{0}^{1}\left|u^{\prime}(s)\right| d s \\
& \leq\left(\int_{0}^{1}|u(s)|^{2} d s\right)^{\frac{1}{2}}+\sqrt{1 / p_{0}}\left(\int_{0}^{1} p(t)\left|u^{\prime}(t)\right|^{2} d t\right)^{\frac{1}{2}} \\
& \leq \sqrt{2 M_{0}}\|u\| .
\end{aligned}
$$

For every $u \in X$, we define the functional $\varphi(u): X \rightarrow R$ by

$$
\varphi(u)=\Phi(u)-\lambda \Psi(u)
$$

here

$$
\Phi(u)=\frac{1}{2}\|u\|^{2}+\sum_{j=1}^{m} \int_{0}^{u\left(t_{j}\right)} I_{j}(s) d s
$$

and

$$
\Psi(u)=\int_{0}^{1} F(t, u) d t
$$

where $F(t, u)=\int_{0}^{u(t)} f(t, s) d s$. 
We easily show that $\varphi$ is differentiable at any $u \in X$ and

$$
\varphi^{\prime}(u) v=\int_{0}^{1}\left(p(t) u^{\prime}(t) v^{\prime}(t)+u(t) v(t)\right) d t+\sum_{j=1}^{m} I_{j}\left(u\left(t_{j}\right)\right) v\left(t_{j}\right)-\lambda \int_{0}^{1} f(t, u(t)) v(t) d t .
$$

Obviously, $\Phi$ is a nonnegative continuously Gâteaux differentiable and sequentially weakly lower semicontinuous functional whose Gâteaux derivative admits a continuous inverse on $X^{*}$, and $\Psi$ is a continuously Gâteaux differentiable functional whose Gâteaux derivative is compact.

Lemma 2.2 ([1]) If $u \in X$ is a critical point of the functional $\varphi$, then $u$ is a classical solution of problem (1.4).

Suppose that $E \subset X$. We denote $\bar{E}^{\omega}$ as the weak closure of $E$, that is, $u \in \bar{E}^{\omega}$ if there exists a sequence $\left\{u_{n}\right\} \subset E$ such that $g\left(u_{n}\right) \rightarrow g(u)$ for every $g \in X^{*}$. Our main tool is the following three critical points theorem obtained in [6].

Lemma 2.3 ([6], Theorem 2.1) Let $X$ be separable and reflexive real Banach space. $\Phi$ : $X \rightarrow R$ a nonnegative continuously Gâteaux differentiable and sequentially weakly lower semicontinuous functional whose Gâteaux derivative admits a continuous inverse on $X^{*}$. $J: X \rightarrow R$ a continuously Gâteaux differentiable functional whose Gâteaux derivative is compact. Assume that there exists $x_{0} \in X$ such that $\Phi\left(x_{0}\right)=J\left(x_{0}\right)=0$ and that

(i) $\lim _{\|x\| \rightarrow+\infty}(\Phi(x)-\lambda J(x))=+\infty$ for all $\lambda \in[0,+\infty)$.

Further, assume that there are $r>0, x_{1} \in X$ such that

(ii) $r<\Phi\left(x_{1}\right)$.

(iii) $\sup _{x \in \overline{\Phi^{-1}((-\infty, r))}} J(x)<\frac{r}{r+\Phi\left(x_{1}\right)} J\left(x_{1}\right)$.

Then, for each

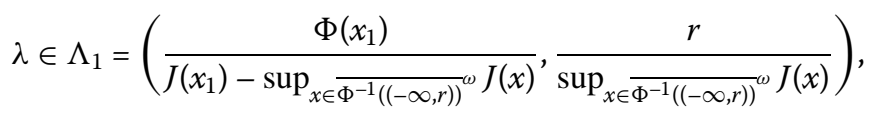

the equation

$$
\Phi^{\prime}(x)-\lambda J^{\prime}(x)=0
$$

has at least three solutions in $X$ and, moreover, for each $h>1$, there exist an open interval

$$
\Lambda_{2} \subseteq\left[0, \frac{h r}{r\left(J\left(x_{1}\right) / \Phi\left(x_{1}\right)\right)-\sup _{x \in \bar{\Phi}^{-1}((-\infty, r))^{\omega}} J(x)}\right)
$$

and a positive real number $\sigma$ such that, for each $\lambda \in \Lambda_{2}$, (1.2) has at least three solutions in $X$ whose norms are less than $\sigma$.

\section{Main results}

Theorem 3.1 The following conditions are given.

$\left(\mathrm{H}_{1}\right) \sum_{j=1}^{m} \int_{0}^{u\left(t_{j}\right)} I_{j}(t) d t \geq 0$. 
$\left(\mathrm{H}_{2}\right)$ Let $a_{i}>0(i=1,2), M>0$, and $0<\mu<2$ such that

$$
F(t, u) \leq a_{1}|u|^{\mu}-a_{2}, \quad \text { for }|u| \geq M, t \in[0,1]
$$

$\left(\mathrm{H}_{3}\right)$ There exist two positive constants $c, c_{1}$ with $c_{1}>\frac{c}{\sqrt{2 M_{0}}}$, such that

$$
4 M_{0} \int_{0}^{1} \max _{|u| \leq c} F(t, u) d t<c^{2}\left(\frac{c^{2}}{4 M_{0}}+\frac{c_{1}^{2}}{2}+\sum_{j=1}^{m} \int_{0}^{c_{1}} I_{j}(t) d t\right)^{-1} \int_{0}^{1} F\left(t, c_{1}\right) d t
$$

Furthermore, put

$$
\begin{aligned}
& \lambda_{1}=\frac{4 M_{0} \int_{0}^{1} \max _{|u| \leq c} F(t, u) d t}{c^{2}}, \\
& \lambda_{2}=\frac{\int_{0}^{1} F\left(t, c_{1}\right) d t-\int_{0}^{1} \max _{|u| \leq c} F(t, u) d t}{\frac{c_{1}^{2}}{2}+\sum_{j=1}^{m} \int_{0}^{c_{1}} I_{j}(s) d s} .
\end{aligned}
$$

Then, for each $\lambda \in\left(\frac{1}{\lambda_{2}}, \frac{1}{\lambda_{1}}\right)$, problem (1.4) has at least three solutions in $X$.

Proof Now we show the conditions (i)-(iii) of Lemma 2.3 are satisfied.

For any $u \in X,|u| \geq M$, and $\lambda \geq 0$, and the assumptions $\left(\mathrm{H}_{1}\right)-\left(\mathrm{H}_{2}\right)$ we have

$$
\begin{aligned}
\Phi(u)-\lambda \Psi(u) & =\frac{1}{2}\|u\|^{2}+\sum_{j=1}^{m} \int_{0}^{u\left(t_{j}\right)} I_{j}(s) d s-\lambda \int_{0}^{1} F(t, u(t)) d t \\
& \geq \frac{1}{2}\|u\|^{2}-\lambda\left[a_{1}|u|^{\mu}-a_{2}\right] \\
& \geq \frac{1}{2}\|u\|^{2}-\lambda\left[a_{1}\left(2 M_{0}\right)^{\mu / 2}\|u\|^{\mu}-a_{2}\right],
\end{aligned}
$$

$0<\mu<2$ implies that

$$
\lim _{\|u\| \rightarrow \infty}(\Phi(u)-\lambda J(u))=+\infty
$$

which shows the condition (i) of Lemma 2.3 is satisfied.

Let $u_{1}=c_{1} \in X$ and $c_{1}>\frac{c}{\sqrt{2 M_{0}}}$. Then

$$
\begin{aligned}
\Phi\left(u_{1}\right) & =\frac{1}{2}\left\|u_{1}\right\|^{2}+\sum_{j=1}^{m} \int_{0}^{u_{1}\left(t_{j}\right)} I_{j}(s) d s \\
& =\frac{1}{2} c_{1}^{2}+\sum_{j=1}^{m} \int_{0}^{c_{1}} I_{j}(s) d s \geq \frac{1}{2} c_{1}^{2}>\frac{c^{2}}{4 M_{0}}=r,
\end{aligned}
$$

so the condition (ii) of Lemma 2.3 is obtained.

By Lemma 2.1, if $\Phi(u) \leq r$, then

$$
|u(t)|^{2} \leq 2 M_{0}\|u\|^{2} \leq 4 M_{0} \Phi(u) \leq 4 M_{0} r=c^{2}, \quad \text { for } t \in[0,1]
$$


which implies that

$$
\Phi^{-1}(-\infty, r) \subseteq\{u \in X,|u(t)| \leq c, t \in[0,1]\} .
$$

So for any $u \in X$, we have

$$
\sup _{u \in \Phi^{-1}(-\infty, r)}^{\omega} \Psi(u)=\sup _{u \in \Phi^{-1}(-\infty, r)} \Psi(u) \leq \int_{0}^{1} \max _{|u| \leq c} F(t, u) d t .
$$

On the other hand, we obtain

$$
\frac{r}{r+\Phi\left(u_{1}\right)} \Psi\left(u_{1}\right)=c^{2}\left[4 M_{0}\left(\frac{c^{2}}{4 M_{0}}+\frac{c_{1}^{2}}{2}+\sum_{j=1}^{m} \int_{0}^{c_{1}} I_{j}(t) d t\right)\right]^{-1} \int_{0}^{1} F\left(t, c_{1}\right) d t .
$$

From the assumption $\left(\mathrm{H}_{3}\right)$ we have

$$
\sup _{u \in \bar{\Phi}^{-1}(-\infty, r)} \omega(u)<\frac{r}{r+\Phi\left(u_{1}\right)} \Psi\left(u_{1}\right),
$$

which shows the condition (iii) of Lemma 2.3 is satisfied.

Note that

$$
\begin{aligned}
& \frac{\Phi\left(u_{1}\right)}{\Psi\left(u_{1}\right)-\sup _{u \in \Phi^{-1}(-\infty, r)} \omega(u)} \leq \frac{\frac{1}{2} c_{1}^{2}+\sum_{j=1}^{m} \int_{0}^{c_{1}} I_{j}(s) d s}{\int_{0}^{1} F\left(t, c_{1}\right) d t-\int_{0}^{1} \max _{|u| \leq c} F(t, u) d t}=\frac{1}{\lambda_{2}}, \\
& \frac{r}{\sup _{u \in \overline{\Phi^{-1}(-\infty, r)}} \Psi(u)} \geq \frac{c^{2}}{4 M_{0} \int_{0}^{1} \max _{|u| \leq c} F(t, u)}=\frac{1}{\lambda_{1}} .
\end{aligned}
$$

The condition $\left(\mathrm{H}_{3}\right)$ implies $\lambda_{2}>\lambda_{1}$. In the light of Lemma 2.3, the problem (1.4) has at least three solutions in $X$ for each $\lambda \in\left(1 / \lambda_{2}, 1 / \lambda_{1}\right)$.

The proof is complete.

\section{Examples}

Consider the following problem:

$$
\begin{aligned}
& -\left(e^{t} u^{\prime}(t)\right)^{\prime}+u(t)=\lambda f(t, u), \quad t \in[0,1], t \neq t_{1}, \\
& \Delta\left(e^{t_{1}} u^{\prime}\left(t_{1}\right)\right)=u\left(t_{1}\right), \quad t_{1}=\frac{1}{2}, \\
& u^{\prime}(0)=u^{\prime}(1)=0,
\end{aligned}
$$

where

$$
f(t, u)= \begin{cases}e^{2 u}, & u \leq 4, \\ u^{1 / 2}+e^{8}-4, & u>4,\end{cases}
$$

then

$$
F(t, u)= \begin{cases}\frac{1}{2}\left(e^{2 u}-1\right), & u \leq 4, \\ \frac{2}{3} u^{3 / 2}+\left(e^{8}-4\right) u+\frac{61}{6}-\frac{7}{2} e^{8}, & u>4 .\end{cases}
$$


Clearly $M_{0}=1$. Let $c=1, c_{1}=4$, it follows that

$$
\begin{aligned}
& 4 M_{0} \int_{0}^{1} \max _{|u| \leq c} F(t, u) d t \\
& =2\left(e^{2}-1\right)<c^{2}\left(\frac{c^{2}}{4 M_{0}}+\frac{c_{1}^{2}}{2}+\sum_{j=1}^{m} \int_{0}^{c_{1}} I_{j}(s) d s\right)^{-1} \int_{0}^{1} F\left(t, c_{1}\right) d t=\frac{2\left(e^{8}-1\right)}{65}, \\
& \frac{1}{\lambda_{1}}=\frac{1}{2\left(e^{2}-1\right)}, \quad \frac{1}{\lambda_{2}}=\frac{32}{e^{8}-e^{2}},
\end{aligned}
$$

which shows that all conditions of Theorem 3.1 are satisfied, so the problem (4.1) admits at least three solutions for $\lambda \in\left(\frac{32}{e^{8}-e^{2}}, \frac{1}{2\left(e^{2}-1\right)}\right)$.

\section{Competing interests}

The author declares that she has no competing interests.

Received: 4 August 2016 Accepted: 6 January 2017 Published online: 18 January 2017

\section{References}

1. Xie, J, Luo, Z: Multiple solutions for a second-order impulsive Sturm-Liouville equation. Abstr. Appl. Anal. 2013, Article ID 527082 (2013)

2. Liang, R, Zhang, W: Applications of variational methods to the impulsive equation with non-separated periodic boundary conditions. Adv. Differ. Equ. 2016, 147 (2016)

3. Li, J, Shen, J: Existence of three solutions to impulsive differential equations. J. Integral Equ. Appl. 24, 273-281 (2012)

4. Li, J, Nieto, JJ: Existence of positive solutions for multi-point boundary value problem on the half-line with impulses. Bound. Value Probl. 2009, Article ID 834158 (2009)

5. $L i, T, L i, J:$ Existence results of second-order impulsive neutral functional differential inclusions in Banach spaces. Adv. Differ. Equ. 2015, 309 (2015)

6. Bonanno, G: A critical points theorem and nonlinear differential problems. J. Glob. Optim. 28, 249-258 (2004)

\section{Submit your manuscript to a SpringerOpen ${ }^{\circ}$ journal and benefit from:}

- Convenient online submission

Rigorous peer review

- Immediate publication on acceptance

- Open access: articles freely available online

- High visibility within the field

- Retaining the copyright to your article 